\title{
Maestro de anestesiología
}

En primer lugar quiero agradecer a la $\mathrm{SACH}$ la oportunidad de hacer este reconocimiento al Dr. Jorge Dagnino. El año 2010 tuve la oportundad de hacer lo mismo, curiosamente aquí mismo en Pto Varas con el Dr. Samuel Torregrosa. Con ambos tuve el privilegio de trabajar muy estrechamente, compartir por años la misma oficina, donde además de beneficiarme de todo lo que representaba el trabajar tan de cerca con ellos, debí fortalecer mi espíritu soportando numerosa bromas que planificaban con el mismo ingenio y agudeza que mostraron durante toda su actividad profesional. Y como lo que no te mata te fortalece, se convirtieron ambos, sin lugar a dudas, en las personas más influyentes en mi desarrollo profesional.

Hacer este discurso no resulta fácil por que conociendo a Jorge imagino que debe estar muy incómodo esperando escuchar hablar de lo mucho que hizo por nuestra especialidad. Pero no hay alternativa. Este reconocimiento de la Sociedad tiene precisamente ese objetivo, el de destacar la labor sobresaliente de una persona que se ha convertido, aún a su pesar, en un modelo, en un referente para sus pares.

Conocí a Jorge Dagnino durante mi primer año de residencia. El venía regresando de Bristol, donde había estado trabajando en el Servicio del Profesor Cedric Prys Roberts, en lo que fue su área de mayor interés clínico, la hipertensión arterial. Hasta antes de su regreso, escuchaba hablar de él como una especie de personaje de leyenda al que todos recordaban, incluso desde su tiempo de alumno cuando era editor del diario de la Escuela de Medicina, El Friday por Medio, en el cual caricaturizó a muchos próceres de esa época; recordaban también su actuar tranquilo y razonado, la capacidad de mantenerse inmutable en las situaciones más críticas, una memoria que le permitía citar cualquier artículo, los cuales además mantenía ordenados y clasificados en múltiples cajas de radiografías que repletaban la estrecha oficina que en esa época era todo el Depto de Anestesiolología de la Universidad Católica. Su llegada sólo vino a confirmar lo que se decía, y se convirtió sin lugar a dudas en uno de los principales impulsores del desarrollo del Depto de Anestsiología de la PUC, del desarrollo de esta Sociedad, y del desarrollo y prestigio de nuestra especialidad.

\section{¿Por que nombrarlo Maestro?}

Para contestar esta pregunta debemos saber que cualidades esperamos posea alguien merecedor de esta calificación. Estas sin lugar a dudas van más allá de la calidad técnica con que alguien puede desarrollar su trabajo como anestesiólogo, dado que finalmente esto puede ser lograda a través del entrenamiento. Como dije el ser considerado maestro es un reconocimiento que hacen los pares a cualidades que deben ser ejercidas en forma permanente, que generen en ellos un modelo, un patrón de comportamiento y desempeño que invita a ser imitado o utilizado como referente, y que finalmente determinan un progreso del sujeto y del grupo. Personalmente creo que la cualidad que más me impresionó fue su gran capacidad de análisis. A muy poco de conocerlo se me hizo evidente que una de sus muy habituales respuestas, la de decir si, no, eventualmente, reflejaba no indecisión, si no que una capacidad de mirar más allá de lo que la mayoría, en un análisis más superficial podía ver. Y como resultado de este análisis nos planteaba siempre, o mejor aún, nos hacía plantearnos varias preguntas adicionales antes de tener una respuesta satisfactoria. Pero además estas respuestas tenían que tener un sustento en información válida, que había que saber donde buscar y luego analizar correctamente. Creo que el mayor aporte docente de Jorge fue el tratar de desarrollar esta capacidad de plantearnos las preguntas necesarias y a través de la enseñanza de la estadística y las actividades de lectura crítica, entregarnos las herramientas para buscar las respuestas. En la situación actual, en la cual los contenidos y destrezas a desarrollar en un programa de residencia aumentan día a día, resulta imprescindible entregar al residente la capacidad de aprender a aprender solo, de manera 
que el proceso de aprendizaje no termine con la residencia, si no que sea un continuo que permita al ex alumno adaptarse y responder a las cambiantes necesidades que enfrentará en su vida profesional.

Esa motivación a la búsqueda de respuestas lleva de manera más o menos natural a las actividades de investigación la cual siempre estimuló y apoyó. En la época en que lo conocí, todos los intentos de hacer algo de investigación más allá de la anestesia cardiovascular, pasaban necesariamente por su revisión y corrección. Revisó cuanto proyecto o trabajo se le hizo llegar, haciendo siempre aportes que mejoraban al original, y enseñándonos a muchos lo que podamos saber de escribir para realizar una publicación, y haciéndonos ver que esto era posible de realizar, que nos atreviéramos a enviar nuestros trabajos a revistas extranjeras, que no importaba que nos rechazaran, que algo aprenderíamos en el proceso. Esa misma actitud lo llevó a ser durante 6 años editor de la Revista Chilena Anestesia, correspondiéndome ser testigo directo de los esfuerzos para juntar el material para logra dar vida a cada número de la revista. Probablemente más de alguno de los presentes se recordará de un editorial titulado algo así como el sueño del editor, y que era una caricatura de él mismo trabajando en la edición de la revista, rodeado de mucho material publicable sin saber cual elegir, o de una página en blanco en que sólo decía trabajo de ingreso: Aquí podría estar el suyo, o de otra página de cartas al editor en que sólo figuraba la pregunta ¿Ud no tiene nada que decir, reportar sugerir o reclamar?. Todo esto reflejaba las dificultades que existían para generar un mínimo de material publicable. Hoy todo ese esfuerzo ha visto resultados, y si bien ese sueño del editor de no saber que elegir para el próximo número aún está pendiente, hoy no es extraño ver publicaciones de autores nacionales en importantes revistas de la especialidad, y que como dije anteriormente en relación a los requisitos para ser maestro, revelan un crecimiento del individuo autor, y también de la especialidad en nuestro país.

Junto a toda esta labor que podríamos llamar académica, Jorge impulsó otra que podría considerarse más bien política. Siempre postuló que los anestesiólogos debían salir del anonimato del pabellón y tener representación en las instancias directivas y de toma de decisiones. Esto no por un afán de figuración si no que por la defensa de nuestros intereses, de nuestras posibilidades de desarrollo, tenían que ser defendidas por los anestesiólogos y no por otros, que sencillamente desconocían nuestro trabajo o que incluso les convenía permaneciéramos en un muy discreto segundo plano. Esto lo llevó a ser a Consejero de Facultad, Director de Post Grado, Vice Decano, y miembro de numerosas comisiones acreditadoras de especialidad. En la Dirección de Post Grado fue probablemente el principal y más importante impulsor en la Facultad de Medicina del desarrollo de la simulación como herramienta docente, la cual fue formalmente incorporada en la actividad de programas de pre y post grado. Esto representa un importantisimo progreso en términos de oportunidad y calidad de la formación, y del respeto y cuidado de la dignidad de nuestros pacientes que siempre debemos tener. Creo que la importancia de esto aún no han sido correctamente dimensionadas, y será como en muchas otras situaciones, el paso del tiempo el que dará la justa medida de su importancia. Sin lugar a dudas en esto tuvo carácter de visionario, del mismo modo que a inicios de los años ochenta lo tuvo la incorporación de la computación a nuestro trabajo habitual, de lo cual fue también fue el principal impulsor. Y aún que no lo crean, esto tuvo opositores.

Las cualidades de un maestro no adquieren su real y completo sentido si no se dan en un contexto de una actitud generosa, que permitan que las cualidades que reconocemos en él lleguen al resto del grupo en el cual se desenvuelve, permitiéndole a ambos ser mejores. Numerosas generaciones de residentes y anestesiológos no relacionados con la UC, la Facultad de Medicina de la UC, y esta Sociedad entre muchos más, pueden dar cuenta de esta permanente actitud de Jorge. Un maestro por esencia comparte, no para mostrar su superioridad, si no que por que no entiende de otra forma el relacionarse con los otros que no sea entregando lo mejor de sí. Todos los que trabajamos con él nos beneficiamos de su permanente disponibilidad para ayudarnos en lo que le solicitáramos, para explicarnos conceptos difíciles los cuales hacía parecer al menos bastante accesibles, o para dejarnos ver la belleza de algunas formas de arte, lo notable de alguna proeza deportiva, o lo que probablemente ha sido su mayor interés en los últimos años, la historia 
de la Medicina, compartiendo con nosotros más de algún episodio en el cual la grandeza del personaje del que nos hablaba radicaba en su capacidad de ver lo que siempre ha estado presente pero que muy pocos perciben o son capaces de hacer evidente. Creo sin lugar a dudas que Jorge ha sido uno de esto personajes, que siempre nos llevó un paso más allá y nos hizo crecer como personas, de manera generosa y cariñosa, que trabajó activa y de manera inteligente por el crecimiento y respeto de nuestra especialidad. Por todo esto nuestra Sociedad le confiere, de manera muy merecida, el título de Maestro de la Anestesiología. 